\title{
Socially Safe Behavior Levels In Online Socialization Process
}

\author{
L. N. Gladkova \\ General and Social Pedagogics Department \\ Institute of Psychology and Pedagogics \\ Tyumen State University \\ Tyumen, Russia \\ Lngladkova13@mail.com
}

\author{
O. A. Selivanova \\ General and Social Pedagogics Department \\ Institute of Psychology and Pedagogics \\ Tyumen State University \\ Tyumen, Russia \\ towerred1966@mail.ru
}

\author{
O. N. Rodina \\ Foreign Languages Department \\ Industrial University of Tyumen \\ Tyumen, Russia \\ olga_rodina2605@mail.ru
}

\begin{abstract}
The article specifies the notions of "social safety" as well as "socially safe behavior" (as constructive behavior leading to successful socialization of individuals, lack of tension, internal and external threats, consistent with the societal norms). The main components' content of readiness for socially safe behavior (value motivational, cognitive, operational active, regulatory, and reflexive) is characterized. It is determined that social safety is manifested at three levels: operational (sensations, feelings, perceptions, thinking, and imagination), tactical (individual direction, individual character characteristics, and world outlooks), strategic (a safe behavior strategy choice in the society). The article describes the experience of socially safe behavior levels diagnostics, as well as the stages and the results of experimental work with teenagers from Tyumen and Tyumen region schools.
\end{abstract}

Keywords-socially safe behavior, levels, operational, tactical, strategic, socially dangerous situation

\section{INTRODUCTION}

Modern studies focus on one of the key characteristics of a new social reality defined as "social instability" which is the ever increasing role of the virtual reality in general and of various Internet resources in particular. Today it is already obvious that the Internet space is a new full-fledged environment for socialization of individuals: young people spend practically all free and academic time in social networks watching videos, downloading music, etc., chatting with friends, finding new acquaintances, search for personally oriented meanings, etc. More than $70 \%$ of schoolchildren of 910 years old, as well as over $90 \%$ of teenagers over 13 years of age, are the constant Internet users. Scholars are talking about the construction of a new type of the social individual. It is called 'Homo Virtualis', 'Homo Cyberus' focused on the virtual world as a creator, a carrier, a consumer of the virtual culture [1].
Online socialization is understood as the process of mastering the norms and values of culture, a personality selfawareness formation which occurs under influence and as a result of modern information and computer technologies of the virtual space in the context of life activity. On the one hand, it has its advantages such as speed and information exchange variety, the possibility of different level and multidirectional communication, etc. On the other hand, it presents a whole spectrum of specific threats such as virtual bullying, sexual and social blackmail, exploitation, harassments etc. Many teenagers are simply not ready to face ant resist them [2]

The problems mentioned above actualize the most important pedagogical task as modern youth socialization namely the formation of personality traits that allow to cope with the changing environment and to confront different risks of the real and virtual spaces (psychological, social, etc.). In pedagogic theory and practice, researchers are searching for ways and means of training children and adolescents for safe behaviors.

Various aspects of both socially risk-taking and socially safe behavior skills formation have been the object of special scholarly research since the second half of the 20th century, in particular: the formation and prevention of risky, socially dangerous, criminal behavior (Ya.L. Gilinsky, V.G. Afanasyev, 1993; E.V. Zmanovskaya, 2003; Richard Dembo, Jennifer Wareham, Norman Poythress, Kathleen Meyers, Brittany Cook BA \& James Schmeidler, 2007) [3-5]; philosophical and methodological problems of safety (Gloria Durka, 2000) [6]; education of safe behavior culture (L.N. Gorina, V.N. Moshkin, A.Popko, 2004) [7]; the construction of pedagogical conditions facilitating the formation of the safe behavior experience (Natasha R. Magson, Rhonda G. Craven, Geoff Munns \& Alexander S. Yeung, 2015 [8]; Carolyn Hilarski, 2004) [9], the readiness for effective actions in extreme situations, for example on the road, in fires, etc. 
(Khromtsova T.G., 2005; Charles Musselwhite, Erel Avineri \& Yusak O. Susilo, 2014) [10-11].

According to Selivanova, Gladkova, the socially safe behavior of adolescents is a behavior consistent with the social norms leading to the successful socialization of the individual, the absence of tension and different threats for both the surrounding people and himself/herself [12].

\section{A. SOCIALLY SAFE BEHAVIOR FORMATION LEVELS}

Assuming that socially safe behavior is formed on the basis of pre-existing readiness for safe behavior, it is pedagogically appropriate to characterize the levels of the formation of socially safe behavior components. the authors defined the levels of socially safe behavior formation on the basis of the level organization of the personal safety (N.L. Shlykova, 2004; O.S. Efimova, 2013; V.A. Popov, A.S. Cherkunova A.S., 2004) [13-15]:

- an operational level (a set of actions which is needed for every minute response to the existing threat to the life and health of a minor dealing with an unpredictable socially dangerous situation caused by a combination of risks); - a tactical level (expedient effective sufficiently stable methods in structure of socially safe behavior aimed at achieving the stated goal to ensure personal and other people safety);

- a strategic level (an established set of mastered methods of socially safe behavior implemented on the basis of the action plan in the system of public relations with the aim of ensuring personal and collective safety).

\section{METHODS}

\section{A. Participants}

The sample comprised 130 adolescents from Tyumen and Tyumen region secondary schools. The participants were equally divided into the experimental and control groups. The education of the experimental group included a programme of teaching teenagers safe behavior in the society with the use of the pedagogical potential of network services. The participants of the control group were educated without using this special programme. The basis of the teaching in the experimental group was an idea of including the actual life experience of the adolescents in resolving macro- and micro social problems: initially - in the virtual space, later - in the real space, and finally - in the group interaction space.

\section{B. The initial stage}

In the beginning of the study, the authors assessed the level of formation of socially safe behavior skill of adolescents with a self-developed diagnostic map. To compile a diagnostic map, the authors used 7 psychodiagnostic techniques: a test for diagnosing the reflexivity level, a Karpov's questionnaire on the basics of life safety, Rokitch's test for value orientations, a questionnaire "Style of behavior selfregulation-98", a Thomas's test for conflictology (a strategy of behavior in conflict situations), a test for determining communicative and organizational orientations, and a test for studying propensity to victim behavior. They were the basis for compiling a diagnostic map for every teenager. According to the data obtained, the participants were divided into 4 groups due to a variant of safe behavior at the personal and social levels. Further on, the education process was carried out according to characteristic features of each group.

The content of the activity on the safe behavior formation of adolescents was carried out at several stages. Assuming that during the experiment, all components of socially safe behavior are formed at each stage, particular attention is paid to the formation of a single component of socially safe behavior at every stage. Due to that, the authors did not single out the goal of the stage because it was the same for all the stages, but they highlighted a priority task for each stage.

\section{The first stage}

A priority task was to form value-motivational and cognitive components of the socially safe behavior of adolescents. The main content of the activity was the purposefully organized inclusion of adolescents by the students of the pedagogical club "5th Floor" in the socially significant projects of the city, the region, the country in the area of creativity, volunteering, vocational guidance, pedagogical detachments. At that stage, the students of the pedagogical club worked with adolescents to raise awareness of the prior values of safety, health, aspiration and the need for personal and public security, aspiration for active productive activities.

\section{The second stage}

A priority task was to form the operational active component of socially safe behavior of adolescents. The main content of the activity was the use of personal experience in demonstrating adolescents' safe behavior in the society at both personal and social levels. In the course of individual and group sessions (consultations, group trainings, discussion and joint viewing of films, videos, creation of collective texts, etc.), adolescents analyzed and discussed personal experiences of safe and dangerous behaviors, developed the ability to anticipate socially dangerous situations, and possible consequences of interaction, found the best ways of safe behavior in accordance with the degree of danger. The main problem solved at that stage was the lack of experience of some teenagers in dangerous behaviors. Therefore films, videos, real facts, and statistics of negative results of socially dangerous behavior of adolescents presented on the Internet were taken for discussions of cause and effect relationships. A special role was played by a system of projects developed with the students of the pedagogical club "5th Floor" to form certain components of socially safe behavior using the pedagogical potential of network services. The formation of safe behavior was largely the result of training the adolescent's safe behavior skills. An important role in shaping behavior was the interaction of adolescents with students (future educators) socialized successful people in the implementation of socially useful activities in the Internet and society. 


\section{E. The third stage}

A priority task was to form the regulatory and reflexive components of socially safe behaviors. The main activities were projects developed by the students of the pedagogical club on the formation of regulatory and reflective components of socially safe behaviors. The dominant means were social services. Their function was direct communication. Their pedagogically relevant elements included the possibility of joint activities of community members. It was important to form a desire to behave safely in the future both for them and for the society, to analyze and assess their behaviors and peers' behaviors. Adolescents were included in the socially significant projects of the pedagogical club of the Institute of Psychology and Pedagogy.

\section{RESULTS}

During the preliminary diagnosis among the adolescents of the control and experimental groups, the authors identified 3 levels of formation of socially safe behavior skills. The initial level of adolescents of the control and experimental groups was the same, tactical. Therefore it was possible to talk about the initially identical levels of socially safe behavior skill formation of adolescents. The groups were approximately of the same number at the operational level (9-10\%), the tactical level (60-62\%) and the strategic level (29-30\%).

The detailed analysis of formation of each socially safe behavior component showed that the operational active, regulatory and reflexive components of the experimental and control group were formed at an insufficient level. These components were sure to be paid special attention to.

Before the implementation of the programme on socially safe behavior formation, the general level of formation of socially safe behavior skill using the pedagogical potential of network services was average (62\%) in the experimental group. The results of processing diagnostic maps of adolescents in the control group revealed that the general level of socially safe behavior skill formation was also average $(60 \%)$.

The control group final diagnosis showed insignificant changes in components. In contrast, the experimental group final diagnosis pointed a significant increase of all indicators especially in cognitive, regulatory and reflexive components of socially safe behavior due to the implementation of the programme on the basis of the use of network services.

The implementation of the programme had significant outcomes. Firstly, the system of adolescents' knowledge improved in the area of possible social dangers of the environment, danger causes, and socially safe behavior rules in the society. Secondly, the emotional and volitional regulation of behavior improved. The adolescents began to plan more consciously and control their actions.

They could make decisions, analyze and evaluate the results of their behavior in socially dangerous situations. They could identify goals and make changes to the programme of actions.
The percentage of adolescents of the experimental group significantly increased at the strategic level and decreased at the tactical and operational levels. In general, the experimental group moved from the general tactical level to the strategic level of socially safe behavior skill formation. As for the control group there were no changes.

\section{DISCUSSION}

When planning and implementing the content of activities for socially safe behavior formation of adolescents, taking into account the identified levels can significantly improve its effectiveness. The authors' study established that the specificity of the subjective perception of the danger degree by a teenager strongly influences the socially safe behavior formation of adolescents. An objectively dangerous situation is often not perceived as dangerous due to high self-esteem, subjectively uncritical assessment of probable risks, nihilistic perception of algorithms and actions for adults in similar situations, and etc.

The authors consider that the process of socially safe behavior formation is built in accordance with the following logic: from the awareness of the existence of objectified risks in the surrounding reality, through the mastery of universal models of response to the gradual transfer of acquired skills to personally relevant situations. The so-called social services can play an important role in the formation process.

A significant area of socialization of modern youth has become the Internet space, the most important form of communication in which there are the so-called social services. Social services are understood to be a complex of network information and communication technologies that supports group interactions.

The compulsory conditions for socially safe behavior formation are, firstly, a comprehensive approach to the education of minors in socially safe behavior through the virtual and real space; secondly, the use of the pedagogical potential of network services; thirdly, the online socialization process; fourthly, the implementation of a programme ("Social networks and you" and "Healthy way of living") through extracurricular activities; fifthly, the organization of logically sustained inclusion of teenagers in socially dangerous situations similar to the reality including the means of network services; and finally, the monitoring of social safety formation.

\section{CONCLUSION}

The problems of personal safety are becoming more and more urgent in the society due to the different risks (political, economic, criminal, military, etc.). Many of them are of social origin. One of the important tasks of educators is to ensure the safety of students through the development of socially safe behavior skills. The adopted logic of the socially safe behavior formation and the prevention of socially dangerous behavior comprise two aspects in modern science. First, an individual is to be consistently aware of personally topical problems and risks of his/her own behavior. Second, he/she is to expand gradually his/her experience in different situations of social 
interactions. However, this study has established that it is impossible to build a socially safe behavior in the accepted logic.

Teenagers meet with various social dangers in both the virtual and the real environment in the society. They can provide personal social safety only if they have formed socially safe behavior. Only having a steady motivation for a socially safe life in the process of online socialization, a system of knowledge, skills and experience of interaction with socially dangerous situations in both virtual and real space, the ability to regulate their own behavior, control and evaluate actions, teenagers can protect themselves from social and psychological dangers and threats, as well as exclude or minimize for others the dangerous situations created by themselves both in the virtual and in the real space.

\section{References}

[1] V.A. Pleshakov, The theory of human cyber socialization. Monograph / Under the Society. Ed. Member of corr. RAO, Ph.D., Professor A. V. Mudrik, Moscow: MPGU; "Homo Cyberus", 2011, 400 p. (in Russian).

[2] K. J. Mitchell, D. Finkelhor, and J. Wolak, "Victimization of Youths on the Internet," Journal of Aggression, Maltreatment \& Trauma, No. 8:1-2, pp. 1-39, 2004.

[3] Ya. I.Gilinsky, and V. G. Afanasyev, Sociology of Deviant Behavior. St. Petersburg: Peter, 1933, 272 p. (in Russian).

[4] E. V. Zmanovskaya, Deviantologiya, Psychology of deviant behavior: Textbook, Moscow: Publishers. Center "Academy", 2003, 288 p. (in Russian).

[5] R. Dembo, J. Wareham, N. Poythress, K.Meyers, B. Cook, and J. Schmeidler, "Continuities in Problem Behavior Among High Risk Youths," Journal of Child \& Adolescent Substance Abuse, No. 16:4, pp. 91-118, 2007

[6] G. Durka, "Teaching youth in a socially toxic environment," Religious Education: The official journal of the Religious Education Association, No. 95:4, pp. 442-452, 2000.

[7] V. N. Moshkin, Raising safety culture school, Barnaul: Barnaul GPU, 2004, 318 p. (in Russian).

[8] N. R. Magson, R. G. Craven, G, Munns, and A. S. Yeung, "It is risky business: can social capital reduce risk-taking behaviours among disadvantaged youth?", Journal of Youth Studies, 2015.

[9] C. Hilarski, "How School Environments Contribute to Violent Behavior in Youth," Journal of Human Behavior in the Social Environment, No. 9:1-2, pp. 165-178, 2004.

[10] T. G. Khromtsova, Education of safe behavior in the life of preschool children, Moscow: Pedagogical Society of Russia, 2005, 80 p. (in Russian).

[11] C. Musselwhite, E. Avineri, and Yu. O. Susilo,"Legitimising risk taking: articulating dangerous behaviour on the road," Transportation Planning and Technology, No. 37:1, pp. 62-82, 2014.

[12] O. A. Selivanov, and L. N. Gladkov "Value concepts of "socially safe behavior" and "socially dangerous behavior" of adolescents in the modern pedagogical science," Vestn.Tyumen State University, vol. 1, pp 198-205, 2015. (in Russian).

[13] N. L. Shlykova, "Psychological safety of the subject of professional activity,"The dissertation of Dr. psychol. Sciences: Moscow, 332 p. (in Russian).

[14] O. S. Elfimova, "Conceptualization of ideas about safety in sociological science, Scientific notes," electronic scientific journal of the Kursk State University, No. 3 (27), vol. 1, 2013. (in Russian).
[15] V. A.Popov, and A. S.Cherkunova "Problem of psychological security and development of social behavior culture of school students," Right and safety, No.4 (13), pp. 35-40, 2004. (in Russian). 